\title{
Global Goals as a Policy Tool: The New School University Intended and Unintended Consequences
}

by Sakiko Fukuda-Parr, Professor of International Affairs,

Despite the increasing use and influence of global goals, little has been written about goal setting as a particular type of policy instrument in global governance. According to the UN intellectual history project (jolly et al, 2009), goal setting originated in the 1960 s and made a major contribution to shaping policy agendas and action. But how and whom does goal setting influence? Goals are set without control over the means of implementation. In an IPC-IG Working Paper, I use ideas from the Sociology of Numbers on 'indicators as a technology of governance' (Merry, 2009) to explore the mechanisms by which global goals create incentives for action and frame thinking, thereby exerting both intended and unintended influence on policy agendas. This One Pager highlights the key points.

Global goals - key features: Policy purpose: Global development goals are international agreements set through diplomatic negotiations in a process to establish norms. They are intended to reaffirm urgent priorities that require international cooperation. Key strengths: Goals go beyond qualitative commitments and spell out time-bound and measurable targets. Quantification makes more rigorous monitoring possible. Simplicity of a time-bound target communicates priorities with effect.

The power of numbers - Studies identify two categories of effects they can have: a governance effect and a knowledge effect. These effects can be illustrated with the case of the Millennium Development Goals (MDGs).

Governance effect - Global goals are used in four different ways:

- communications or a messaging device to express important priorities, raise awareness and mobilise attention;

- evaluative framework for monitoring progress towards important social objectives;

- accountability framework to assess compliance with commitments made; and

- planning targets to guide programming of resources, efforts and policy design.

The governance effects operate largely through mechanisms of self-regulation, where individuals and organisations respond to the message of moral appeal, and where countries seek to do well in international assessments and maintain good standing in the development community. However, the use of goals in direct control, either as accountability or planning frameworks, reveals a methodological incoherence.

Knowledge effect - While numbers are used to describe a social condition, the reverse can also take place; numbers can take on the role of defining concepts (Merry, 2009). In the process, they can shift meanings.

Quantification expressing social phenomena inherently involves a process of:

- reductionism and simplification of complex phenomena such as'poverty' or'development';

- reification of intangible human and social conditions such as'suffering' and'deprivation'; and

- abstraction of experiences out of their historical and locational contexts.

The case of the MDGs - The MDGs had positive governance effects as a communications device and a monitoring framework.
Reductionism, reification and abstraction were key MDG strengths that helped build international consensus. They have been effective as a communications tool for raising awareness and advocating for anti-poverty initiatives, and they became the common framework for monitoring development progress across multiple reports.

But when interpreted as planning targets, the MDGs generated much criticism, such as: methodologically incoherent; inadequate as a development strategy; biased against poorest countries by setting a one-size-fits-all target without considering initial conditions. Moreover, they were set through a process of norm setting and by international negotiations without local participation. For these reasons, they are inappropriate as a framework for accountability. Applied as planning targets, the goals have the potential to distort priorities, especially by sidelining important objectives that are not included in the framework. The reductionism, simplification and abstraction of the goals also leave out complex contextual challenges and processes.

The MDGs' knowledge effects could have far-reaching implications for the future of development cooperation. They were introduced to communicate poverty eradication as a priority and to monitor its progress, but they have come to be a substitute for defining poverty and the broader challenge of development. The quantification of these concepts involved reductionism, reification and abstraction, and a reframing of these challenges. Left outside the framework are the complex challenges of ending poverty: the vast array of forms that 'poverty'takes as a social reality; context-specific root causes of poverty that are structurally embedded in power structures; and the intangible condition of poverty as loss of agency, freedom and dignity.

This reframing has important implications for driving the thinking about priority agendas. Thus the MDGs have generated criticism from civil society groups, particularly human rights advocates, for leaving out inequality, participation, accountability and governance from the framework. Similarly, the root cause of poverty in weak productive capacity of economies has also been left out, thus generating criticism from economists for leaving out 'development'.

Intended and unintended consequences - Global goals have proven to be powerful tools of global governance to promote human development. Yet their effects go well beyond drawing attention to important priorities. They also have governance and knowledge effects that have far-reaching implications for development thinking, narratives deployed by governments, donors and other stakeholders, and thus the political economy that drives international economic decision-making. A multi author independent research project-Power of Numbers: Critical Review of MDG Targets for Human Development and Human Rights — is investigating these implications for 11 targets. Findings will be published in 2013.

References:

Jolly, R., L. Emmerij and T. Weiss (2009). UN Ideas that Changed the World. Bloomington, Indiana University Press.

Merry, S.E. (2009). 'Measuring the World: Indicators, Human Rights and Global Governance', Current Anthropology, 52 (83): 83-95. 